\title{
Campanhas de prevenção a incêndios florestais na V\&M Florestal
}

\author{
Antônio Claret de Oliveira' \\ Guilherme Dias de Freitas ${ }^{2}$ \\ Michelle Alves Moura ${ }^{3}$
}

\section{RESUMO}

Atualmente torna-se cada dia mais preocupante e agravante o problema dos incêndios no Brasil, seja pela dimensão preventiva ou pelo combate que ainda é carente de recursos mais eficientes. E, a cada ano, o fogo vem provocando mudanças importantes nos ecossistemas florestais trazendo com isso grandes prejuízos ambientais e econômicos ao país. A V\&M Florestal vem atuando no sentido de sensibilizar empresas e órgãos públicos, buscando parcerias para realização de ações efetivas de prevenção e conscientização da população em geral.

\section{INTRODUÇÃO}

Criada em 1969 com o objetivo de desenvolver alternativa de geração de energia renovável, em substituição ao carvão mineral para atender à demanda energética da atividade siderúrgica da VALLOUREC \& MANNESMANN TUBES - V \& M do BRASIL S.A., a V \& M Florestal, instalou-se no Norte e Noroeste do Estado de Minas Gerais, onde promove a atividade de florestamento utilizando o Eucalyptus spp, destinado à produção de carvão vegetal.

Esta região, onde predomina o bioma do cerrado, utilizada historicamente com a pecuária extensiva, passou com a implantação da V \& M Florestal, bem como de outras empresas do setor, a ser utilizada para a instalação de diversos projetos florestais.

1 - Superintendente Geral

2 - Gerente de Administração e Meio Ambiente

3 - Auxiliar

V \& M FLORESTAL - Praça Voluntários da Pátria, 81 - 35790.000 Curvelo - MG - Brasil -

Tel.: 38-721-6000 - Fax. 38-721-6013 - E-mail: vmflorestal@ vmtubes.com.br 
As condições áridas do cerrado das áreas de atuação da empresa, caracterizadas pela precipitação média anual de $1.148 \mathrm{~mm}$ reduzida e concentradas aproximadamente $90 \%$ nos meses de Outubro a Março pela temperatura média anual de $24,3^{\circ} \mathrm{C}$, reúnem variáveis favoráveis à ocorrência e propagação de incêndios florestais.

A proteção ao patrimônio florestal e ambiental, sempre constituiu preocupação da empresa, desencadeando processo de melhoria contínua/desenvolvimento tecnológico aplicáveis nas diversas etapas da atividade da empresa, dentre estas a Prevenção e Combate aos Incêndios Florestais.

\section{CAMPANHAS DE CONSCIENTIZAÇÃO INTERNA E EXTERNA}

A prevenção é a melhor estratégia de controle de incêndios. Nesta visão, a V\&M Florestal vem realizando, há vários anos, campanhas de Prevenção e Combate a Incêndios Florestais junto a seus funcionários, vizinhos e comunidade local.

Das ocorrências de incêndio registradas na empresa, $70 \%$ são originadas externamente, e em grande parte, nas margens das rodovias. Eles podem causar grandes prejuízos, tais como:

ß Incêndios às propriedades próximas às margens das rodovias causando sérios prejuízos às plantações;

B Acidentes com veículos e a morte de pessoas provocada pelo fogo e a fumaça;

ß Danos ao abrigo e a alimentação para os animais e os filhotes não conseguem fugir e morrem queimados; 


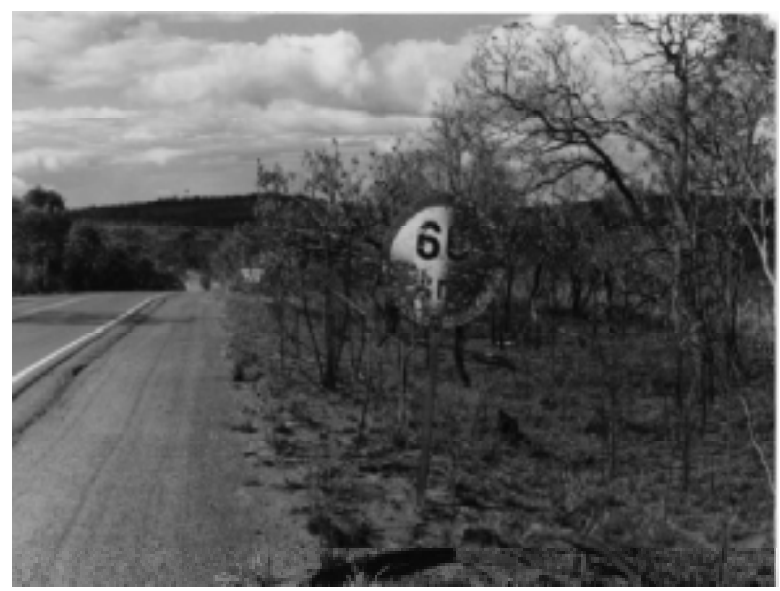

B Danos às placas de sinalização tornando as estradas inseguras;

ß Destruição da cobertura vegetal que amortece a força da chuva provocando erosão e assoreamento dos rios;

B Incêndios em veículos com material combustível (caminhões com madeira, carvão, gasolina, gás, etc.);

ß A chuva não entra no solo queimado, deixando de abastecer os lençóis subterrâneos de água, responsáveis pela alimentação das nascentes, rios, cisternas e poços.

Em 1999, buscando maior abrangência e ação para os incêndios originados nas margens das rodovias, a empresa firmou parceria com o Instituto Estadual de Florestas-IEF e a Polícia Rodoviária Federal para desenvolvimento da Campanha de Prevenção Contra Incêndios Florestais, com ênfase ao público constituído pelos motoristas e usuários das rodovias de acesso ao norte e noroeste do estado de Minas Gerais. O objetivo era transmitir ao público alvo informações básicas sobre a campanha, os malefícios do fogo, originado principalmente na beira das rodovias e como se prevenir contra os incêndios. 


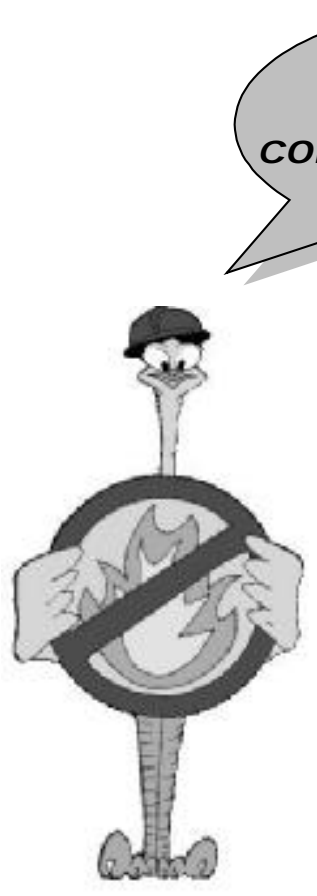

Florema foi desenvolvido um "Concurso para Escolha de Nome na Ema" onde foi escolhido o nome Florema. Além do concurso, foram realizados internamente diversos treinamentos, palestras.

\section{NÚMEROS CARACTERÍSTICOS REFERENTES AOS INCÊNDIOS FLORESTAIS NA V\&M FLORESTAL:}

\section{A. Média anual de áreas queimadas por categoria}

Neste gráfico, observamos a média histórica anual (1995 a 1999) de áreas queimadas por categoria (Eucalipto: 16\% e Reserva + Regeneração não conduzida: $84 \%$ ) sendo portanto necessário, intensificar os esforços na detecção/combate e ações preventivas nas áreas de cobertura vegetal nativa. 


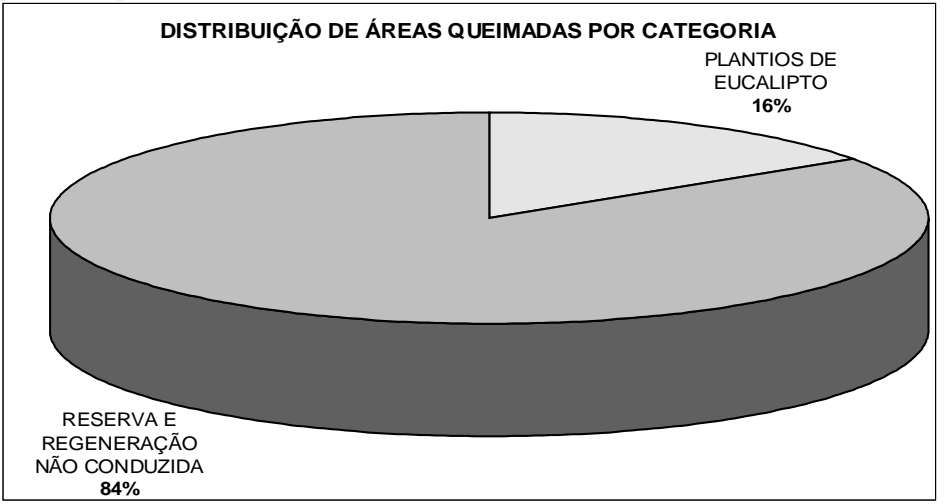

B. Média anual de áreas queimadas por ocorrência

Este gráfico demonstra a média anual de áreas queimadas por ocorrência. No último ano obtivemos o melhor índice onde reduzimos a área queimada por incêndio.

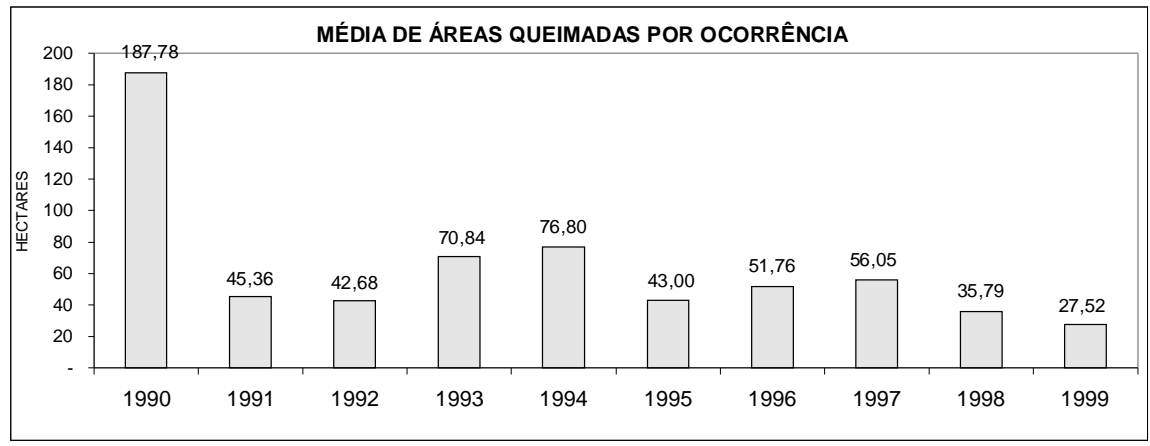




\section{Precipitação Mensal X Ocorrências De Incêndios.}

Observamos neste gráfico a média histórica anual demonstrando o percentual mensal de precipitação e ocorrências sendo o mês de Junho o mês mais seco e o mês de Setembro o mês com maior número de ocorrências.

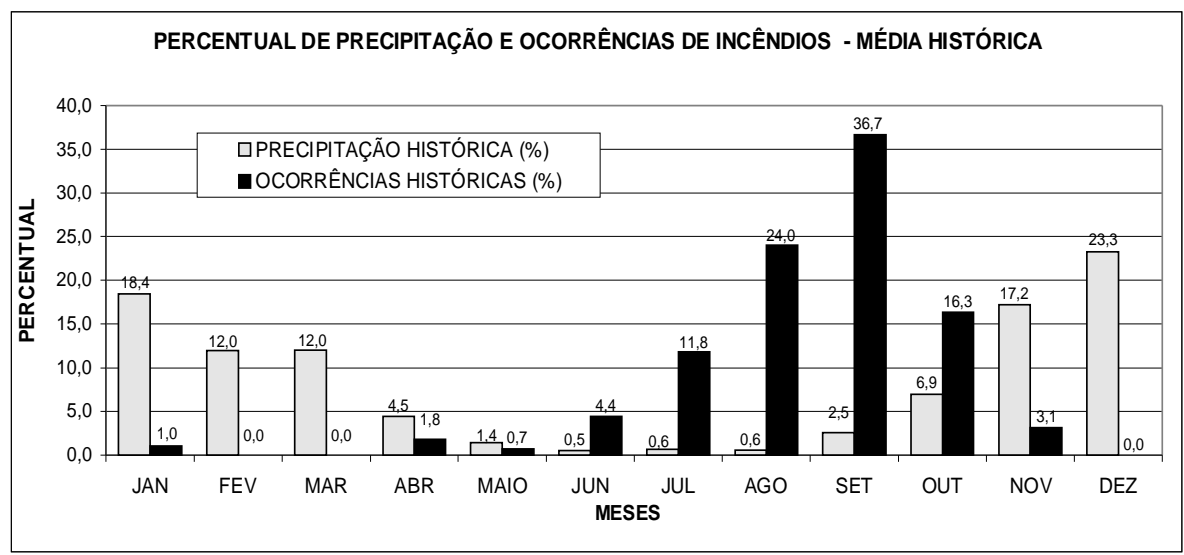

D. Origem das ocorrências de incêndio.

Este gráfico demonstra a origem histórica das ocorrências de incêndio sendo de origem externa os incêndios causados por motivos vindos de fora da área da empresa como: margens de rodovia, confrontantes, queima de pasto, incendiários, minhoqueiro, etc. e de origem interna os incêndios causados por motivos vindos de dentro da empresa, das operações florestais como fagulha de descarga de trator, fumante, etc. 


\section{AÇÕES PRIORIZADAS:}

Anualmente, contínuos investimentos têm sido destinados em trabalhos de prevenção, treinamentos e equipamentos de combate aos incêndios na V\&M Florestal.

Em 1999, esses trabalhos foram intensificados com parcerias firmadas entre o Instituto Estadual de Florestas - IEF e a Polícia Rodoviária Federal permitindo redução dos valores relacionados às ocorrências de incêndios obtidos em relação aos outros anos.

Com as crescentes alterações climáticas mundiais, a estratégia de se enfrentar o problema do fogo em conjunto com outras empresas e instituições representa uma das poucas opções viáveis para controle destas ocorrências que podem provocar sérios prejuízos ao patrimônio florestal e ambiental brasileiro.

Priorizamos, portanto a implementação de ações sobre ocorrências de origem externa, com trabalhos de conscientização junto aos proprietários vizinhos e na busca de parceiros para realização de trabalhos de sensibilização com os motoristas das rodovias que dão acesso às áreas da empresa através de blitz ecológica e distribuição de material informativo; realização de simulações de incêndio testando e melhorando os tempos de detecção, comunicação e chegada da equipe para o combate; aprimoramento dos Treinamentos de Brigadas com utilização de novas técnicas para combate; ampliação à proteção de áreas de reserva; aumento da largura dos aceiros externos; desenvolvimento de novas técnicas de manutenção; aumento do número de torres de vigilância e aquisição de caminhões bombeiro.

\section{AGRADECIMENTOS}

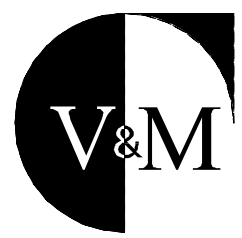

VALLOUREC \& MANNESMANN TUBES 